\title{
The Carrying Capacity of the Reinforced Timber Beams
}

\author{
Kristyna Vavrusova \\ VSB-Technical University Ostrava, Faculty of Civil \\ Engineering: Ostrava, Czech Republic \\ e-mail: kristyna.vavrusova@vsb.cz \\ * Corresponding Author \\ David Mikolasek \\ VSB-Technical University Ostrava, Faculty of Civil \\ Engineering: Ostrava, Czech Republic
}

\author{
Libor Zidek \\ VSB-Technical University Ostrava, Faculty of Civil \\ Engineering: Ostrava, Czech Republic
}

\begin{abstract}
The content of this article is destructive laboratory testing of timber beams with threated glued-in steel rods to the possibility of describing the behavior of these beams under load and determine the interaction of a wooden beam with glued-in steel rods.
\end{abstract}

Keywords-destructive testing; timber;glued-in

\section{INTRODUCTION}

Each of the materials used in the building industry has its advantages and disadvantages. Their mutual combination (in this case, low weight of wood and high tension strength of steel) can achieve the desired properties of the resulting composite material.

Composite timber-concrete structures are currently becoming quite commonplace of contemporary building industry. Nowadays also composite timber-steel structures started to be used in building engineering.

This article is therefore focused on verifying the possibility of using reinforced timber structures with threated steel rods.

From the past and present experiments are known results which are based on glued-in steel elements into the timber profiles [1].

There are already known some outputs of laboratory tests that with gluing-in of steel will increase the mechanical properties of the timber element, but these tests are just at the beginning.

Testing of these types of structures is already in the world progress, see for example [2 and 3] but different types of steel elements and placing of them in the tested elements still offers the opportunity to explore and discover new findings that may lead to a better understanding of the behavior and carrying capacity of structures and expansion of their use in practice.

For testing were chosen glued beams with glued-in threaded rod with a diameter of 6 and $8 \mathrm{~mm}$, which were tested on a four-point bending test according to EN 408 methodology.

For comparison, of sample breach type and determination of the maximum fracture force was also created and tested a set of samples without glued-in steel threaded rods.

\section{METHODS AND SOLUTIONS}

\section{A. Test samples}

For testing there were assembled 3 sets, comprising of 10 test samples each (see Fig .1.):

A) Test samples without glued-in steel rod

B) Beams with glued-in steel rod of $6 \mathrm{~mm}$ diameter

C) Beams with glued-in steel rod of $8 \mathrm{~mm}$ diameter
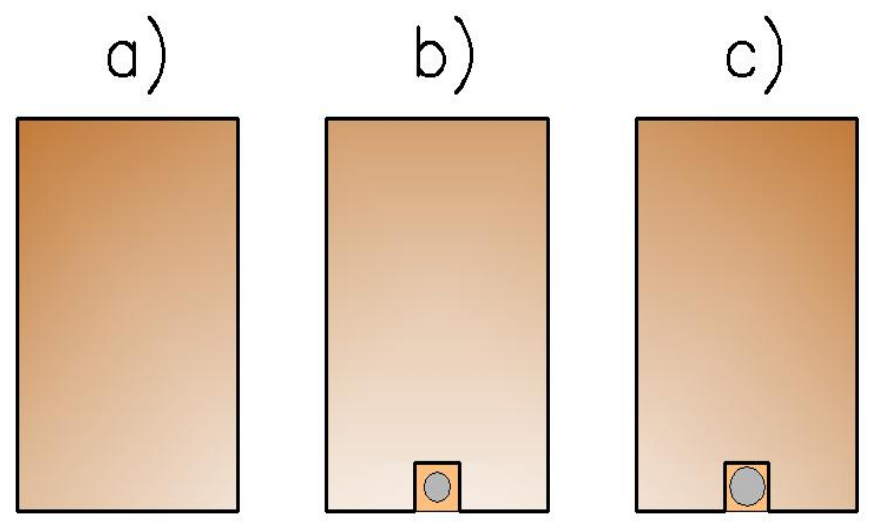

Figure 1. Test samples

Material of the threaded rod - steel of strength class 8.8 with diameters 6 and $8 \mathrm{~mm}(\mathrm{fu}=800 \mathrm{MPa})-$ see Fig .2. 


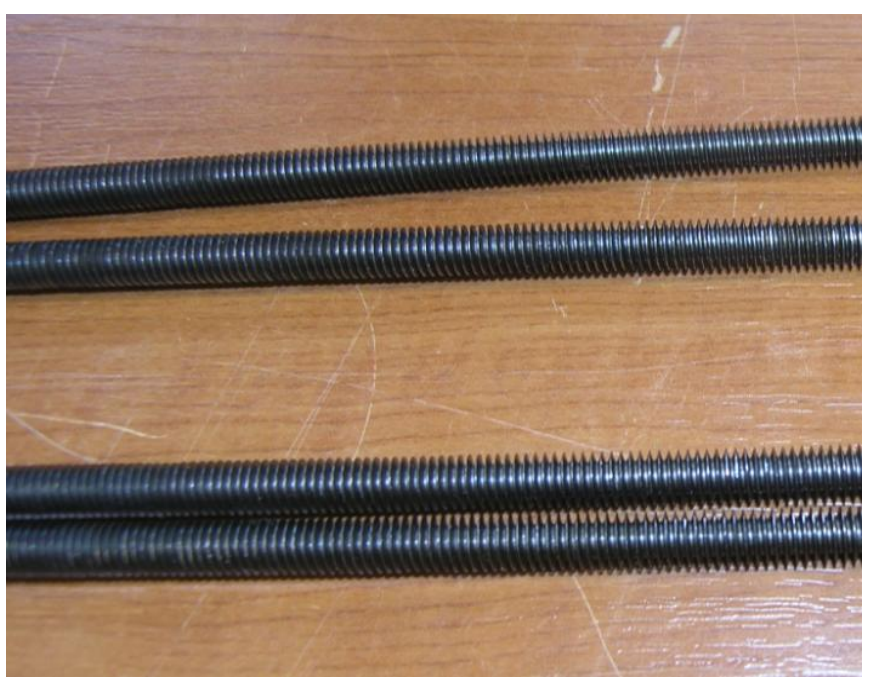

Figure 2. Steel threaded rods

For gluing-in of steel threaded rods was used the biocomponent epoxy adhesive XEPOX with low viscosity and high wetting power (see Fig .3).

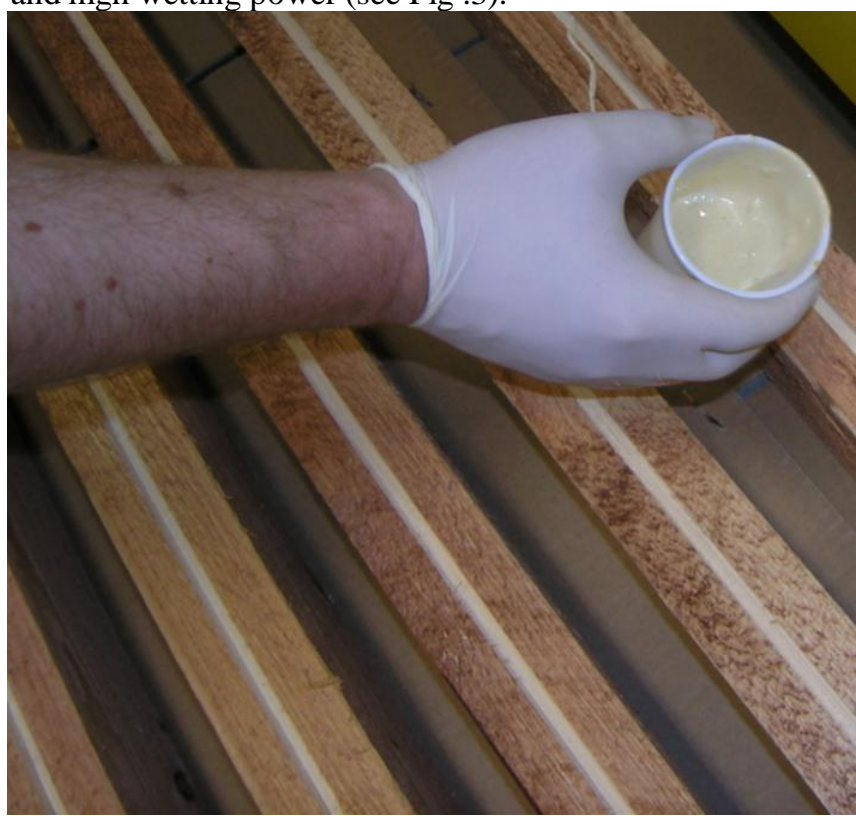

Figure 3. Gluing-in of steel rods

The test samples were conditioned prior to destructive testing in standard ambient temperature $(20 \pm 2){ }^{\circ} \mathrm{C}$ and relative humidity $(65 \pm 5) \%$. To determine and verify the test samples moisture was used moisture detector.

\section{B. The course of the static tests}

The testing was proceeded on a hydraulic pressure machine EU40 at laboratories of Faculty of Civil Engineering, VSB-Technical university Ostrava, while the force into the tested beam was increased gradually according to the scheme for bending test given in EN 408 (see Fig.4).



Figure 4. Bending test scheme

The chosen rate of the displacement of the jaws of the press seems to be optimal, because the failure of all the tested samples appeared in a time-boundary of $300 \pm 120$ sec according to EN 408 [4], which corresponds to the interval of laboratory tests for short-time strength according to the current European standards for timber structure Eurocode 5 [5].

The test sample fixing to the hydraulic press is shown in the Fig .5. The test sample was loaded with increase of deformation within the specified time so the resulting carrying capacity wasn't significantly affected by the speed of loading.

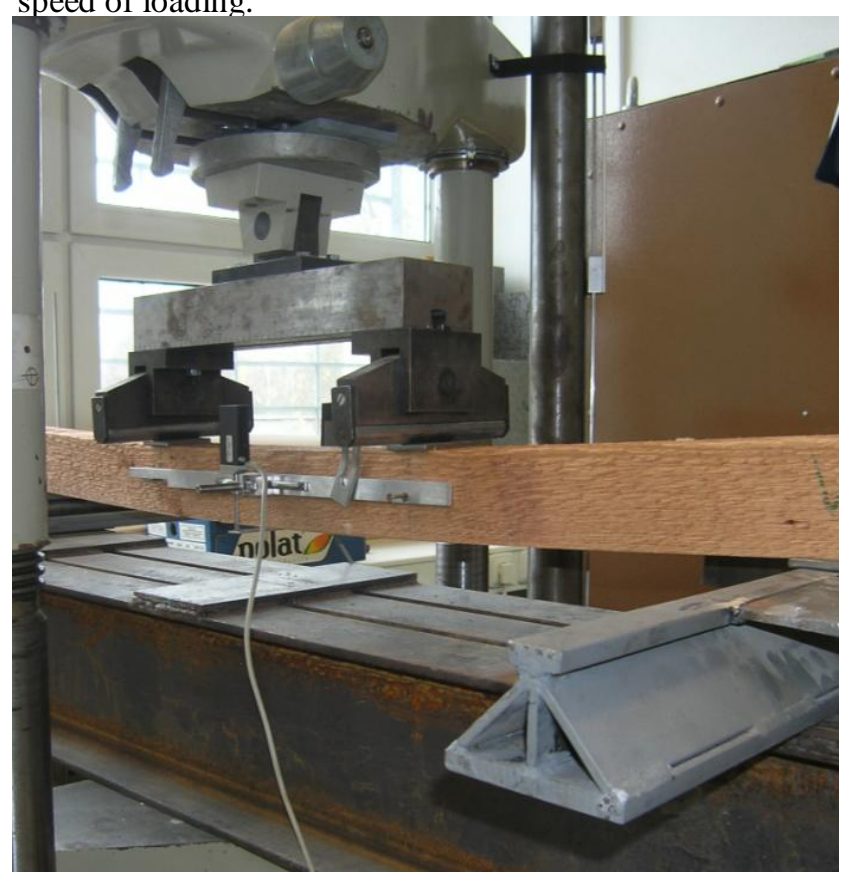

Figure 5. Fixing into the hydraulic press

\section{RESULTS}

When testing the set of sample A without glued-in threaded steel rods, the mean value of the fracture force of the set is $15.20 \mathrm{kN}$.

The breach of the samples occurred primarily on tension edge of the beam in the midspan region (at the point of maximum bending moment) - see Fig .6. 


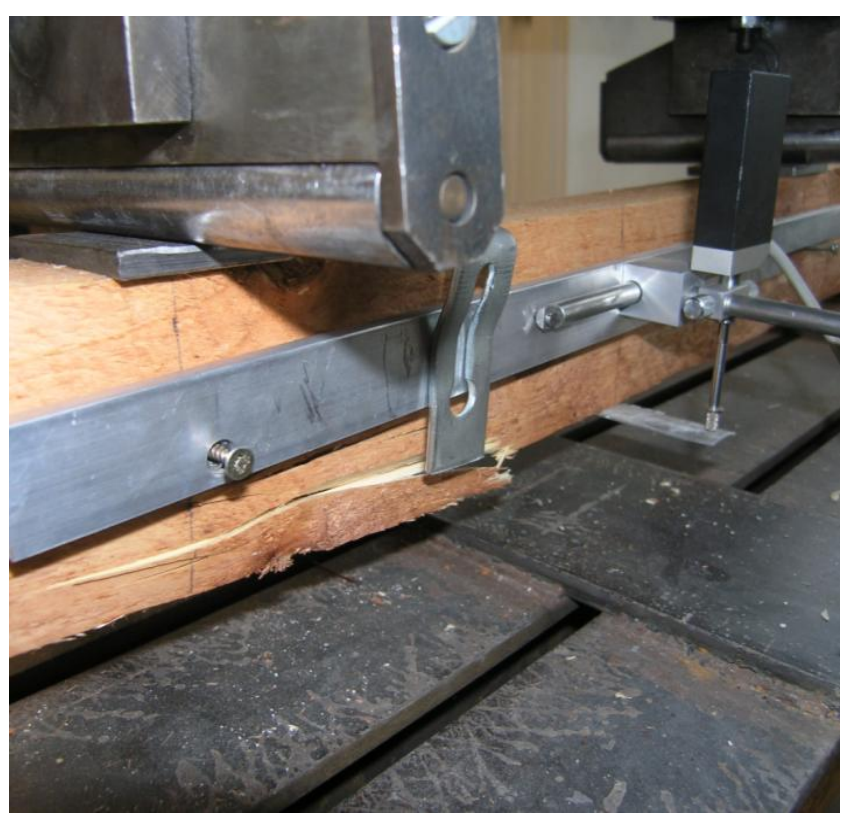

Figure 6. The typical breach of test samples in set A (without glued-in steel threaded rod)

When testing the set of samples $B$ with glued-in threaded steel rod with diameter of $6 \mathrm{~mm}$ the mean value of the fracture force of the set is $17.12 \mathrm{kN}$.

The typical breach of these beams was break of the threaded steel rods under load - i.e. - exceeded bearing capacity of steel threaded rods in tension (see Fig .7).

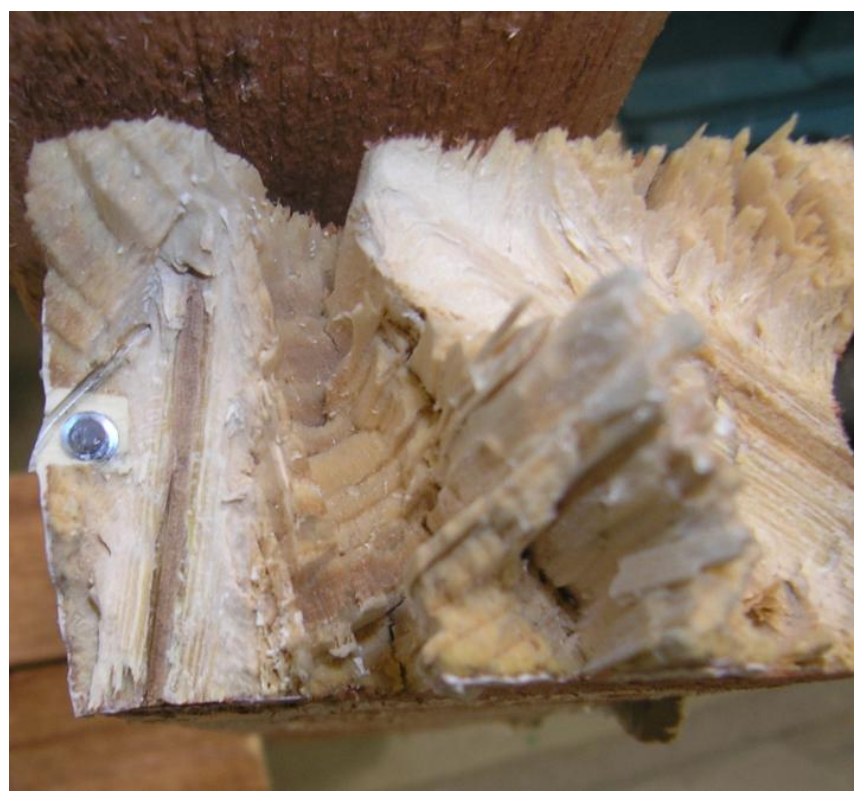

Figure 7. The typical breach of test samples in set B (with glued-in steel threaded rod with diameter of $6 \mathrm{~mm})$

When testing the set of samples $\mathrm{C}$ with glued-in threaded steel rod with diameter of $8 \mathrm{~mm}$ the mean value of the fracture force of the set is $17.81 \mathrm{kN}$.

These beam breach occurred primarily in wood parallel with the grains usually in the bottom third of the height of the cross-section. In the threaded rod while achieving maximum breach force, the tensile strength wasn't exceeded (see Fig. 8).

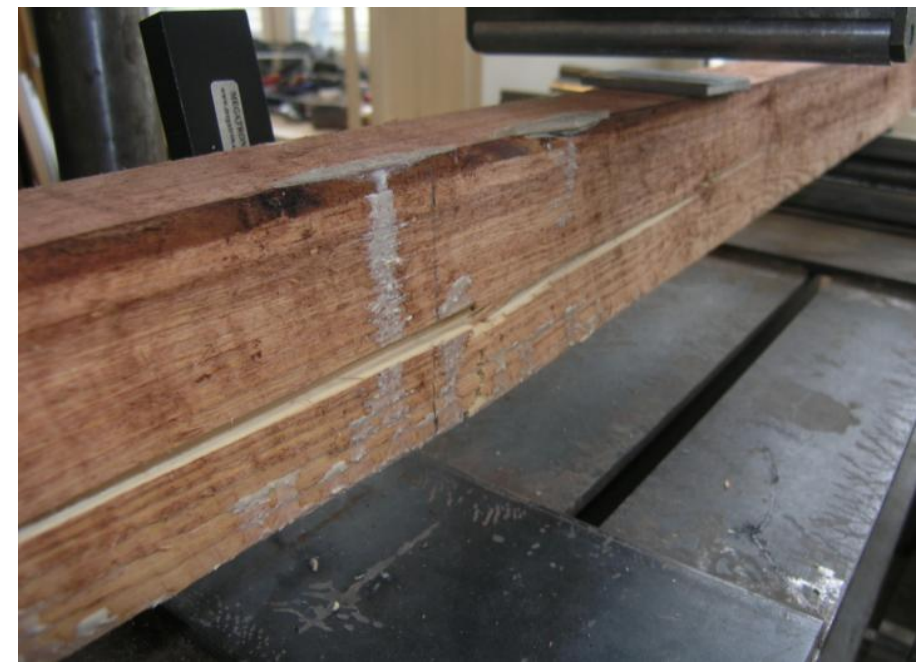

Figure 8 . The typical breach of test samples in set $\mathrm{C}$ (with glued-in steel threaded rod with diameter of $8 \mathrm{~mm}$ )

\section{CONCLUSIONS}

Based on the obtained values is evident that the value of the fracture force of the beam without glued-in steel rods is the smallest with the value of $15.12 \mathrm{kN}$. When using a threaded glued-in rod with a diameter of $6 \mathrm{~mm}$, the value of fracture force increased to $17.12 \mathrm{kN}$.

The highest value of the fracture force has the set of samples $\mathrm{C}$ with a value of $17.81 \mathrm{kN}$. As can be seen the value of the fracture force increases with the diameter of the threaded rod, but in such a small cross-sections there is no interaction between the steel rod and the wooden beam under load. This solution is therefore suitable for larger sizes beams.

\section{ACKNOWLEDGEMENT}

This outcome has been achieved with funds of Conceptual development of science, research and innovation assigned to VŠB - Technical University of Ostrava by Ministry of Education Youth and Sports of the Czech Republic.

\section{REFERENCES}

[1] Smith, T., Pampanin, S., Fragiacemo, M., Buchanan, A., Design of constructions of prestressed timber buildings for seismic areas, In World conference of Timber Engineering (WCTE), 2008, Japan.

[2] Gustafsson J., Serrano E., Aicher S. and Johansson C.J., Strength design equation for glued-in rods, International RILEM Symposium Joints in timber structures, Stuttgart, 2001.

[3] Klajmonová, K., Lokaj, A., 2013: Round timber bolted joints with mechanical reinforcement, in: Proceedings of the the 2nd Global Conference on Civil, Structural and Environmental Engineering (GCCSEE 2013). Shenzhen, China, September 28-29, 2013. In: Advanced Material Research 2013. 838-841, Pp. 629-633.

[4] EN 408 Timber structures. Structural timber and glued laminated timber. Determination of some physical and mechanical properties, 2010.

[5] Eurocode 5: Design of timber structures - Part 1-1: General Common rules and rules for buildings, Czech Standards Institute, 2006. 